\title{
AGE-DEPENDENT LONG-TERM ADAPTATION OF CRAYFISH PHASIC MOTOR AXON SYNAPSES TO ALTERED ACTIVITY
}

\author{
G. A. LNENICKA AND H. L. ATWOOD \\ Department of Physiology, University of Toronto, Toronto, Ontario, Canada M5S 1A8
}

Received May 1, 1984; Revised July 2, 1984; Accepted July 9, 1984

\begin{abstract}
Crustacean tonic and phasic motoneurons have neuromuscular synaptic properties corresponding with their functional requirements. Phasic axon synapses produce large excitatory postsynaptic potentials (EPSPs) which depress rapidly during repetitive activation. Tonic axon synapses generally produce smaller EPSPs which are more resistant to fatigue. To test whether nerve impulse activity of the motoneuron plays a role in the establishment of these synaptic properties, a phasic axon was tonically stimulated in vivo.

The "fast" closer excitor of the crayfish claw, which normally fires few impulses, was stimulated for $2 \mathrm{hr} /$ day at $5 \mathrm{~Hz}$, through implanted electrodes. In young crayfish, this stimulation produced an 11 -fold decrease in synaptic fatigue at the fast axon's neuromuscular synapses, as determined from measurements of EPSPs during $5 \mathrm{~Hz}$ stimulation of the fast axon for $30 \mathrm{~min}$. In comparison with EPSPs of the contralateral control claw, the initial EPSP amplitude was $44 \%$ smaller and the final EPSP amplitude was 4.3 times larger for the chronically stimulated fast axon. These changes in EPSP amplitude are due to changes in transmitter release. This longterm adaptation of the fast axon to imposed tonic activity persists for at least 10 days after the effect has been established.

The same chronic stimulation regimen produces significant, although less dramatic, results in adult crayfish. Compared to the contralateral control, the chronically stimulated fast axon showed no change in initial EPSP amplitude and only a 2 -fold increase in the EPSP amplitude after $30 \mathrm{~m} . \mathrm{n}$ of stimulation at $5 \mathrm{~Hz}$. Thus, the decrease in synaptic fatigue was only 2 - to 3 -fold, much less than in young crayfish.

During normal growth, the fast axon synapses become better suited to their phasic pattern of activation, showing progressive increase in initial EPSP amplitude and greater synaptic fatigue during prolonged activation. In light of our findings, it is suggested that activity levels during development may play a role in the establishment of the adult synaptic properties.
\end{abstract}

Do synapses adapt to the functional requirements presented by their pattern of activation? This question can be addressed at the neuromuscular junction, where differences in transmitter output are matched to patterns of activity, generally classified as phasic or tonic. Immobilization of a tonic vertebrate muscle, producing a more phasic firing pattern, results in greater release of transmitter from the neuromuscular synapses at low frequencies of stimulation, and greater synaptic depression at higher frequencies (Robbins and Fischbach, 1971). These characteristics of transmitter release are normally associated with phasic muscle (Gertler and Robbins, 1978). However, chronic stimulation of a phasic motor nerve with a tonic pattern of activation did not result in tonic-type neuromuscular synapses (Gertler and Robbins, 1978).

We further tested the role of motoneuron activity in the establishment of neuromuscular synaptic properties by tonically stimulating an identified phasic crayfish motoneuron in vivo. In addition, the effect of developmental stage upon the modifiability of neuromuscular synapses was tested.

The crustacean neuromuscular system offers many advantages for the study of the influence of activity upon synaptic performance. The small number of motoneurons allows the normal activity of an identified motoneuron to be determined and its activity artificially altered for an extended period of time. In addition, there is a broad range of activity levels among identified crustacean motoneurons and large corresponding differences in neuromuscular synaptic properties.

As in vertebrates, crustacean motoneurons can be broadly classified as phasic or tonic based upon their activity and synaptic properties (Atwood, 1973). During low frequency activation, axons of phasic motoneurons generally produce relatively large postsynaptic potentials which fatigue rapidly when evoked at moderate frequencies. Axons of tonic motoneurons show little fatigue during prolonged stimulation and typically generate large postsynaptic potentials only when activated at higher frequencies. 'These synaptic properties allow the phasic motoneuron to produce maximum muscle contraction with few impulses, while the tonic motoneuron is able to maintain and grade tension through its prolonged activity and broad range of impulse frequencies.

In order to judge the role that activity plays in the development and maintenance of adult synaptic properties, activity and synaptic potentials of an identified phasic motoneuronthe "fast" excitatory neuron of the crayfish claw closer muscle (Wiersma, 1961) - were monitored during growth. The effect of imposed tonic activity upon synaptic properties of this neuron in young and adult crayfish was determined. We found that during growth, the phasic axon's synaptic properties gradually 
become better suited for its normal phasic pattern of activation. In young crayfish, the phasic axon's synapses adapt to imposed tonic activity by becoming more fatigue resistant. This longterm adaptation to imposed tonic activity persists for at least 10 days. Plasticity decreases during aging: imposition of tonic activity in the adult has a significant, although less dramatic, effect than in the young crayfish.

\section{Materials and Methods}

Chronic stimulation and recording. A preparation for chronic stimulation and recording was developed in order to study normal activity of the fast axon and experimentally alter this activity (Fig. 1). Multistranded Teflon-coated stainless steel wire (Medwire Corp.), selected for its strength and flexibility, was used for stimulation and recording. The Teflon insulation was removed from the end of the wire, which was reduced to a single strand. The single strand of wire was inserted through a small pin hole in the exoskeleton and quickly affixed to the exoskeleton with Grip (alkyl- $\alpha$-cyanoacrylate). A layer of 5-min expoxy (Devcon) was applied to cover the implantation site and the wire. If the epoxy was allowed to cure sufficiently before returning the animal to the water, the electrodes would remain in place for weeks. One pair of electrodes was implanted in the propodite over the closer muscle to record myograms, and a second pair was implanted in the meropodite over the main claw nerve for chronic stimulation.

During chronic stimulation, the crayfish were placed in small containers and the two pairs of short $(4 \mathrm{~cm})$ wires were connected via miniature alligator clips to stimulator and amplifier leads. The stimulating voltage was adjusted to recruit the fast axon. The large amplitude of the electromyogram permitted unambiguous identification of the fast axon's activity (Fig. 1).

For chronic recording in the unrestrained animal, long recording wires were used, allowing the animal to move freely in the holding tank. The electrical activity (myogram) of the closer muscle was recorded on tape with a Hewlett Packard 3964A Instrumentation tape recorder. Fast axon electromyograms were counted during playback by triggering a Tektronix 468 digital storage oscilloscope. Each myogram represents one impulse in the fast axon.

Acute measurements of synaptic potentials, input resistance, and transmitter release. For measurement of excitatory postsynaptic potentials (EPSPs) and quantal content, an isolated claw was set up for intracellular recording. The opener muscle was removed, exposing the dorsal surface of the closer muscle. The large nerve bundle containing the fast axon was exposed in the meropodite and stimulated electrically with a suction electrode. This isolated preparation was maintained in
Van Harreveld's solution (Van Harreveld, 1936), containing $10 \mathrm{mM}$ HEPES buffer, at $20^{\circ} \mathrm{C}$. Conventional intracellular recording techniques were employed, using microelectrodes filled with $3 \mathrm{M} \mathrm{KCl}$ and having tip resistances of 5 to 10 megohms.

The input resistance of the muscle fiber was determined by passing current with an intracellular electrode and recording the change in potential with a second intracellular electrode. The two electrodes were positioned in the middle of the fiber with an electrode separation of approximately $50 \mu \mathrm{m}$. The amount of current injected was measured with a virtual ground circuit connected to the bath.

Quantal content of transmitter release was determined by recording focally on the surface of a muscle fiber with extracellular microelectrodes filled with Van Harreveld's solution and connected to a virtual ground circuit, for measurement of synaptic current. The extracellular electrodes were prepared by scoring and breaking a microelectrode to produce a tip with an inside diameter of approximately $20 \mu \mathrm{m}$. The electrode tip was then polished briefly with a heating filament during observation with a dissecting microscope; care was taken not to decrease the tip diameter appreciably. The extracellular measurement of synaptic current with the virtual ground circuit produced a better signal-to-noise ratio than did the measurement of extracellular synaptic potentials by voltage recording. By careful positioning of the electrode to maximize the signal amplitude, asynchrony of transmitter release could normally be detected. Asynchronous unitary currents provided a measure of quantal unit size (see also Johnson and Wernig, 1971). The mean number of quanta released per impulse (quantal content, $m$ ) was determined from the ratio of average evoked current amplitude to mean unitary current amplitude.

All comparisons of samples for the determination of significant differences were performed using a Student's $t$ test.

Crayfish size classes. Crayfish were grouped into four size classes for analysis of synaptic properties during growth and the effect of imposed tonic activity. Small crayfish had claw lengths of 0.5 to $0.7 \mathrm{~cm}$, carapace lengths of 1.2 to $1.4 \mathrm{~cm}$, and weighed approximately $0.5 \mathrm{gm}$; their estimated age was 2 to 4 months. Intermediate crayfish had claw lengths of 1.0 to $1.2 \mathrm{~cm}$, carapace lengths of 2.1 to $2.7 \mathrm{~cm}$, and weighed approximately $3.5 \mathrm{gm}$; their estimated age was 6 to 8 months. Corresponding values for small adult crayfish were: 2.0 to $2.5 \mathrm{~cm} ; 3.4$ to 4.4 $\mathrm{cm} ; 11 \mathrm{gm}$; and 1 to 2 years. For large adult crayfish values were: 4.0 to $5.0 \mathrm{~cm} ; 4.6$ to $5.3 \mathrm{~cm} ; 40 \mathrm{gm}$; and 2 years. Animals with regenerated claws were not used.

\section{Results}

Synaptic properties of the fast axon during development. The closer muscle of the crayfish claw is innervated by two excit-
Figure 1. Schematic diagram of the crayfish claw showing the location of the closer and opener muscles (stippled area), and the placement of the stimulating and recording electrodes. The myograms produced by stimulation of the fast and slow motor axons are shown Calibration: $20 \mathrm{msec}, 2 \mathrm{mV}$.

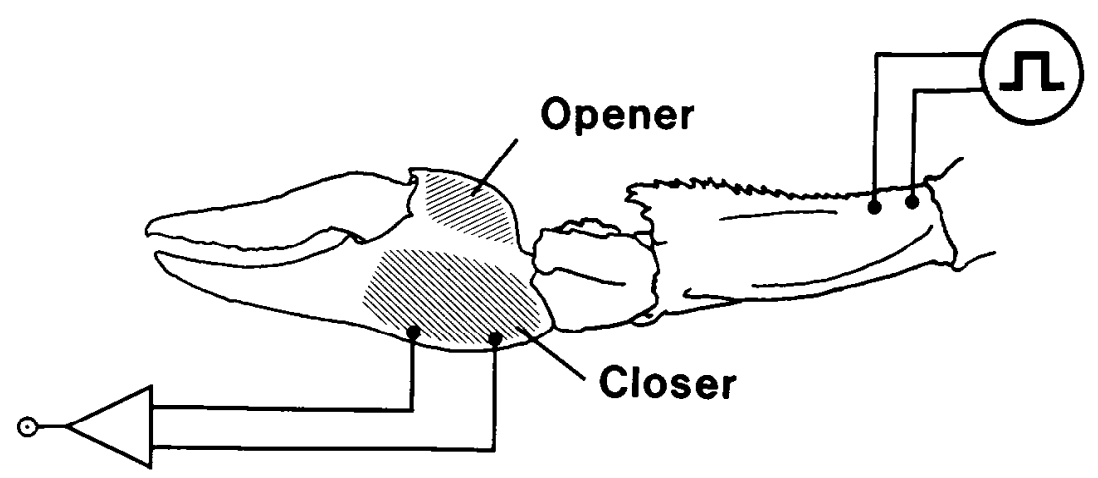

"Fast" axon 
atory axons and one inhibitory axon. The phasic "fast" closer excitor produces rapid closing of the claw with only a single activation. The more tonically active "slow" closer excitor requires repeated activation in order to close the claw; however, it can produce more sustained contraction than the fast excitor. The synaptic properties of the fast axon were studied during growth of the crayfish using an identified group of fast axon synapses. EPSP amplitudes were measured in muscle fibers in the distal third of the dorsal surface of the closer muscle. This region of the muscle was selected because it is readily accessible, strongly innervated by the fast axon, and relatively weakly innervated by the slow axon. Also, unlike some of the deeper fibers, those in this region rarely produced a muscle spike at the frequencies of stimulation employed, permitting easy measurement of EPSP amplitudes.

Throughout this study, synaptic properties were characterized by two measurements: synaptic potential amplitude during brief, low frequency $(0.01 \mathrm{~Hz})$ stimulation; and change in synaptic potential during prolonged stimulation at a moderate frequency $(5 \mathrm{~Hz})$. Initial EPSP amplitude was determined from the mean response to eight stimulations delivered at $0.01 \mathrm{~Hz}$ and measured using a signal averager. Changes during prolonged stimulation were determined by sampling responses over a period of $30 \mathrm{~min}$ of stimulation at $5 \mathrm{~Hz}$.

In adult crayfish, these fast axon synapses produce a large initial EPSP which depresses dramatically during continuous stimulation at a moderate frequency (Fig. 2A). The initial (low frequency) EPSP amplitude is represented as the zero time value in Figure 2 and throughout the remainder of the study.

These characteristics, typical of phasic crustacean axons (Atwood, 1973, 1982), were found to be gradually acquired during maturation. In small animals, these fast axon synapses produce a small initial EPSP which facilitates during the first few minutes of stimulation at $5 \mathrm{~Hz}$ (Fig. $2 \mathrm{C}$ ), only showing depression during the later stages of the stimulation period. This conversion of synaptic performance, from low-output facilitating to high-output depressing synapses, occurs gradually during growth. Fast axon synapses of intermediate-sized crayfish have intermediate properties (Fig. 2B).

Myograms indicate that, in general, the total population of fast axon synapses is undergoing a change similar to that seen in the selected population of synapses during this period of growth. In small animals, myogram amplitudes show facilitation during $5 \mathrm{~Hz}$ stimulation and are still elevated after $30 \mathrm{~min}$ of stimulation. This contrasts markedly with the dramatic depression of the myogram seen in adult crayfish during $5 \mathrm{~Hz}$ stimulation. However, even in small crayfish, a single impulse in the fast axon is sufficient to produce rapid closing of the claw. Thus, it is likely that the relatively small initial EPSP found in the superficial muscle fibers of small crayfish is not characteristic of all of the fibers.

Since synaptic depression (Elmquist and Quastel, 1965) and facilitation (Dudel and Kuffler, 1961b) at neuromuscular junctions are due to the pattern of transmitter release, changes in these properties during growth are most probably the result of alterations in the population of presynaptic terminals innervating the muscle fibers. Since synapses are continually added during growth of crustacean muscle fibers, whereas others are removed (Govind, 1982), such a change could occur if the synapses formed later were more phasic in their properties than those formed early. This transformation would also occur if all synapses were more tonic in their properties, when initially formed, and gradually acquired their phasic phenotype. We wished to determine whether the pattern of ongoing activity in the motoneuron can play a role in establishing these synaptic properties.

Normal activity of the fast axon. The normal activity of the fast axon was determined by monitoring closer muscle my- ograms daily during a 10-hr period (8:00 PM to 6:00 AM). Records were made from animals kept in separate tanks and capable of normal locomotion. The spontaneous activity was recorded on tape, and the fast axon myograms were counted during playback. For each animal, the amplitude and waveform of the fast axon myogram were determined by evoking a fast axon response through electrical stimulation of the claw nerve. Since the myogram of the fast axon was the same for evoked and spontaneous activity, it could be easily identified (Fig. 3).

Eight crayfish (four large adults, four intermediate) were monitored for an average of 3.6 days each. The mean number of fast axon spikes per hour was $0.44 \pm 0.11$ (representing mean $\pm \mathrm{SE}$ throughout the text). When the fast axon was active, only a single impulse normally occurred. During $290 \mathrm{hr}$ of recording, closely spaced impulses were only observed once.

This low level of spontaneous activity is consistent with the high threshold for activation of the fast closer excitor observed during the study of tactile and proprioceptive claw reflexes (Wiens and Gerstein, 1976). In contrast, the slow axon is often active at high frequencies.

When activity of intermediate and large adult crayfish was compared, there was no significant difference in the fast axon activity (large adult, $0.47 \pm 0.08$ spikes/hr; intermediate, 0.40 \pm 0.1 spikes/hr). Thus, the fast axon is rarely active, and there are no dramatic changes in its activity during growth from intermediate-sized to adult crayfish.

Chronic recording of closer muscle myograms in restrained, recently hatched crayfish ( $<1$ month old) indicate that, at least qualitatively, the tonic slow axon and the phasic fast axon have their characteristic firing patterns very soon after eclosion. We were not able to obtain data from very small, freely moving animals.

Long-term adaptation to imposed activity. To examine the role of activity in the establishment of the fast axon's synaptic properties, chronic stimulation was applied unilaterally to the fast axon ( $5 \mathrm{~Hz}$ for $2 \mathrm{hr} /$ day for 2 weeks). One day following the last stimulation period, acute experiments were performed with isolated claws to compare synaptic properties in the experimental and contralateral control claws. Due to the age dependence of the synaptic properties and possible age-dependent differences in synaptic plasticity, crayfish were divided into various size groups for analysis of data derived from chronic stimulation.

The effect of the chronic stimulation regimen upon the fast axon's synaptic properties in intermediate-sized crayfish is shown in Figure 4. The initial EPSP amplitude is significantly less in the experimental claw $(4.78 \pm 0.89 \mathrm{mV})$ than in the contralateral control $(8.56 \pm 1.01 \mathrm{mV} ; p<0.05)$. In addition, the synapses of the chronically stimulated fast axons are fatigue resistant. After 30 min of stimulation, the EPSP amplitude in the experimental claw $(4.26 \pm 0.78 \mathrm{mV})$ is significantly larger than in the control claw $(1.01 \pm 0.26 \mathrm{mV} ; p<0.05)$. Thus, the synapses adapt to applied stimulation by producing a smaller EPSP during low frequency activation and a larger EPSP during maintained repetitive activity. This change adapts the synapses for prolonged moderate frequency activation and, at the same time, leaves them less adapted for low frequency activation. The application of Martin's correction factor for nonlinear summation of quantal units (Martin, 1955) to these data does not change any of these relationships.

Changes in transmitter release. To determine whether the changes in EPSP amplitude produced by conditioning are due to changes in the amount of transmitter released, muscle fiber input resistance $\left(R_{\mathrm{o}}\right)$ and quantal content of transmitter release were measured (Fig. 5). Crustacean muscle fibers have distributed innervation; therefore, quantal content measurements were made using extracellular focal recording (Dudel and Kuffler, 1961a). Since locating an "active site" with the extracel- 
Figure 2. Synaptic properties of the fast closer excitor during growth. EPSPs were measured in distal muscle fibers on the dorsal surface of the closer muscle during continuous $5-\mathrm{Hz}$ stimulation of the fast axon. EPSP amplitudes were determined at various intervals during stimulation by signal averaging 16 responses. The initial EPSP amplitude (zero time) was determined from eight stimulations at $0.01 \mathrm{~Hz}$. Each graph represents the mean EPSP values from 20 to 30 fibers in 10 to 15 claws. Bars indicate the standard error of the mean. $A$, Small adults. Inset: Representative EPSPs at 0,10 , and $30 \mathrm{~min}$. $B$, Intermediatesized animals. $C$, Small animals. Inset: Representative F.PSPs at 0,10 , and $30 \mathrm{~min}$. Calibrations: $20 \mathrm{msec}, 5$ $\mathrm{mV}$.

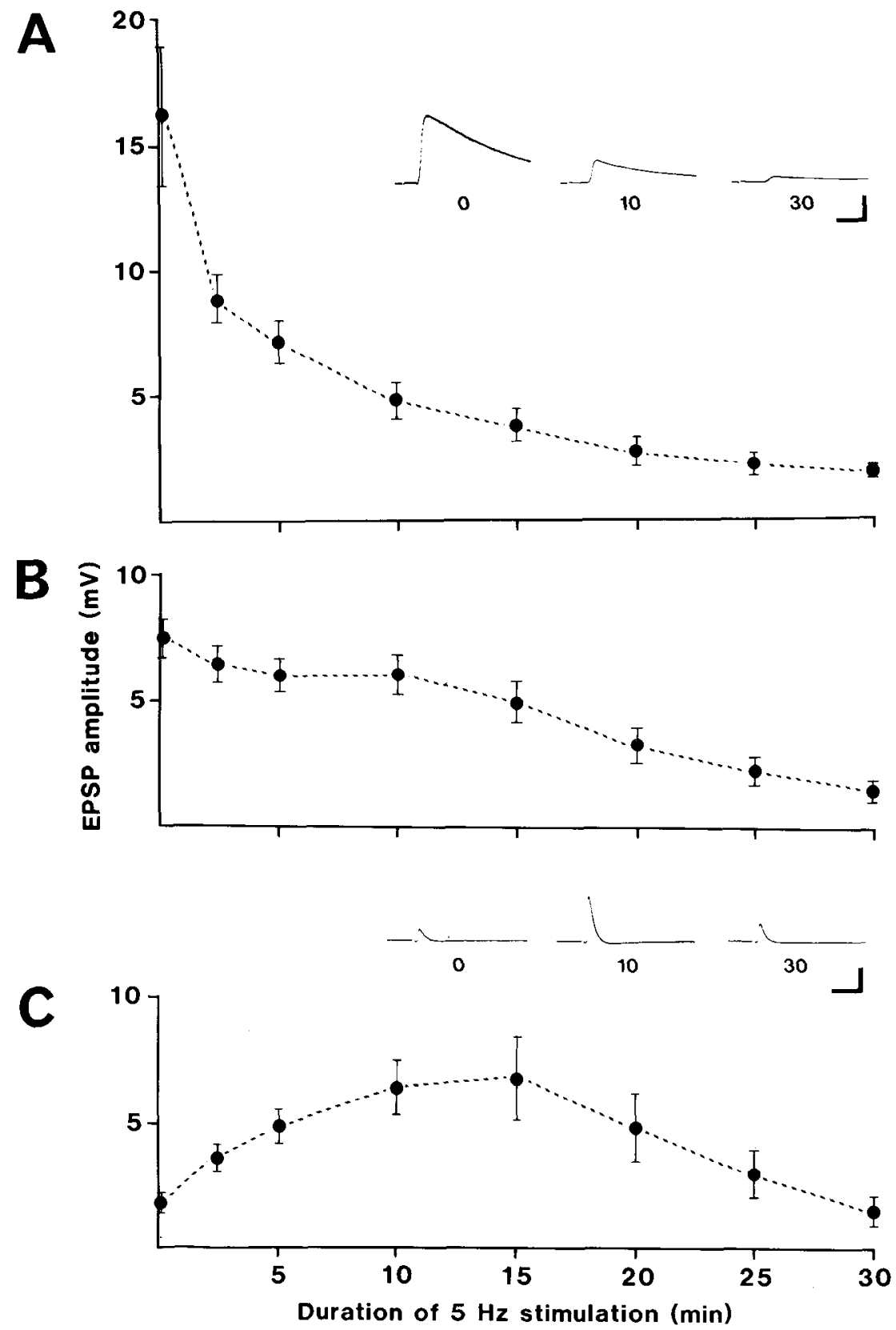

lular electrode required repetitive activation of the synapses for periods of minutes, the quantal content could not be measured during low frequency activation or during the early stages of 5 $\mathrm{Hz}$ stimulation. Instead, quantal content was measured after $40 \mathrm{~min}$ of $5 \mathrm{~Hz}$ stimulation, normally allowing sufficient time to locate an active site with each of the two extracellular electrodes employed. These measurements were made to determine whether the greater EPSP amplitude found in the experimental claw after $30 \mathrm{~min}$ of stimulation at $5 \mathrm{~Hz}$ is due to greater transmitter release. In addition, muscle fiber $R_{o}$ was measured to check for possible changes in the passive electrical properties of the postsynaptic muscle fiber.

Six intermediate-sized animals were stimulated for periods ranging from 10 to 18 days (mean, 14.2 days), and quantal content measurements as well as measurements of $R_{0}$ were made 1 day following the final stimulation period. After $40 \mathrm{~min}$ of stimulation. mean quantal release was determined. Mean quantal content in the control claw was $0.45 \pm 0.13(n=10)$. Quantal release in the experimental claw $(1.18 \pm 0.20 ; n=11)$ was significantly greater $(p<0.05)$. There was no significant difference $(p>0.05)$ in the time constant of decay of the unitary synaptic currents in the control claws $(2.00 \pm 0.11$ msec, $n=6$ active sites) compared to the experimental claws $(2.11 \pm 0.22 \mathrm{msec}, n=7$ active sites). Since the duration of the quantal current at the crustacean neuromuscular junction is probably determined by the average lifetime of the singlechannel conductance (Crawford and McBurney, 1976), chronic stimulation appears to produce no change in the kinetics of the postsynaptic channels.

The chronic stimulation regimen did not alter the muscle fiber's input resistance. Measurements of $R_{\mathrm{o}}$ in the experimental claw $(391.3 \pm 32.7$ kilohms; $n=12)$ were not significantly different $(p>0.05)$ from those in the contralateral control claw $(390.6 \pm 66.6$ kilohms; $n=10)$. The $\mathrm{I}-\mathrm{V}$ curves in both experimental and control claws were approximately linear within 10 $\mathrm{mV}$ of the resting potential. Hyperpolarizations or depolarizations greater than approximately $20 \mathrm{mV}$ produced rectification in both groups. Input resistance values were determined from the slope of the $I-V$ curve between the resting potential and depolarization of $10 \mathrm{mV}$. 


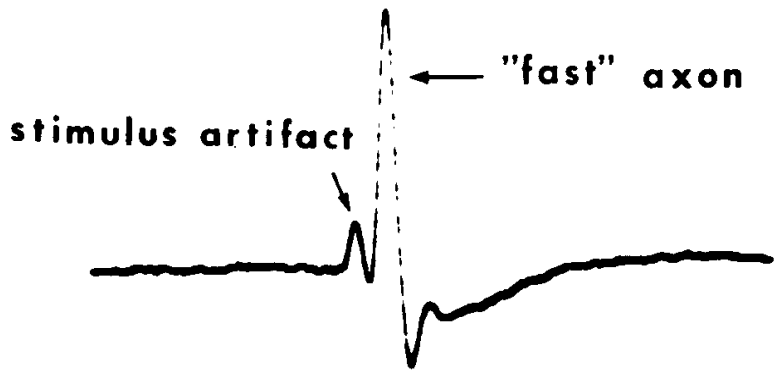

EVOKED

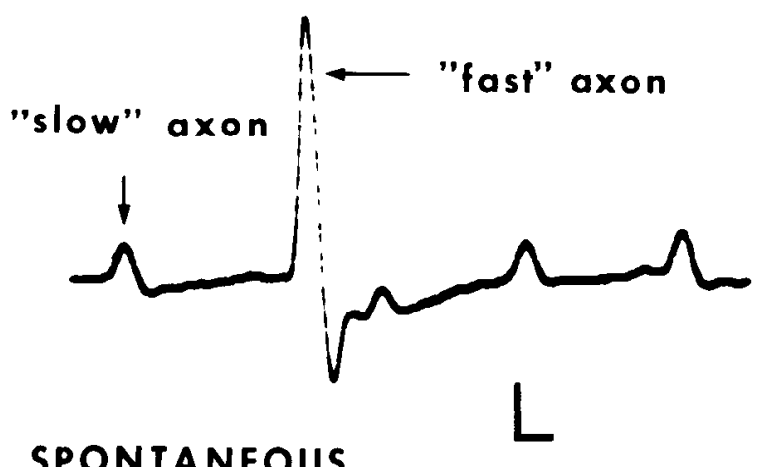

\section{SPONTANEOUS}

Figure 3. Measurement of fast axon activity. The normal activity of the fast axon was determined by monitoring its activity in a relatively unrestrained preparation (see "Materials and Methods"). Top trace, A fast axon myogram evoked by electrical stimulation of the nerve. Bottom trace, A fast axon myogram occurring spontaneously during the animal's normal activity. Note the presence of the slow axon myograms occurring at a high frequency. Due to the consistent amplitude and waveform of the fast axon myogram it could be identified during the animal's normal activity. Calibration: $5 \mathrm{msec}, 1 \mathrm{mV}$.

These results indicate that the larger EPSP amplitude in the experimental claw measured after $30 \mathrm{~min}$ of $5 \mathrm{~Hz}$ stimulation is due to a greater release of transmitter. Based upon the similarity of $R_{\mathrm{o}}$ in experimental and control muscle fibers, the smaller initial low frequency EPSP of experimental claws probably reflects a smaller initial synaptic current. Such a reduction in synaptic current could be produced by a decrease in the amount of transmitter released (lower quantal content) or a decrease in the sensitivity of the postsynaptic membrane. Quantal content measurements provided no evidence for a decreased sensitivity of the postsynaptic membrane or for changes in the kinetics of the postsynaptic channels in the experimental claw. Thus, the most probable explanation for the smaller initial EPSP amplitude is a decrease in the amount of transmitter released.

Plasticity is lost during aging. To determine whether the effects of conditioning are age dependent, adult crayfish were subjected to the same regimen of chronic stimulation as the younger animals. Adult crayfish were divided into two size classes, both of which were chronically stimulated $2 \mathrm{hr} /$ day at $5 \mathrm{~Hz}$ for 2 weeks. The synaptic properties were then tested 1 day after the last stimulation period. The effect of the stimulation regimen upon the synaptic properties in small adults is shown in Figure 6. There was no significant change in the initial EPSP amplitude. The EPSP amplitude after $30 \mathrm{~min}$ of stimulation at $5 \mathrm{~Hz}$ was significantly larger $(p<0.05)$ in the experimental $(3.65 \pm 0.58 \mathrm{mV} ; n=10)$ compared to the control claw $(1.70 \pm 0.17 \mathrm{mV} ; n=10)$. However, experimental synapses still show dramatic synaptic depression. The response of large adults to chronic stimulation was found to be similar. The application of Martin's correction factor (Martin, 1955) to these data does not change any of these relationships.

The magnitude of the change produced by imposed activity was found to be less in both small and large adults than in the intermediate-sized crayfish. This is indicated by the significantly greater increase in synaptic endurance in small animals compared to adults ('I'able 1). 'I'here was no significant difference in the magnitude of the change in synaptic endurance produced by chronic stimulation when small and large adults were compared $(p>0.05)$. However, imposed tonic activity produced a significantly greater increase in synaptic endurance in intermediate-sized animals compared to adults $(p<0.05)$

Time course of the change in synaptic properties. To determine the time course of establishment of the long-term adaptation and its decay, the myogram was monitored during

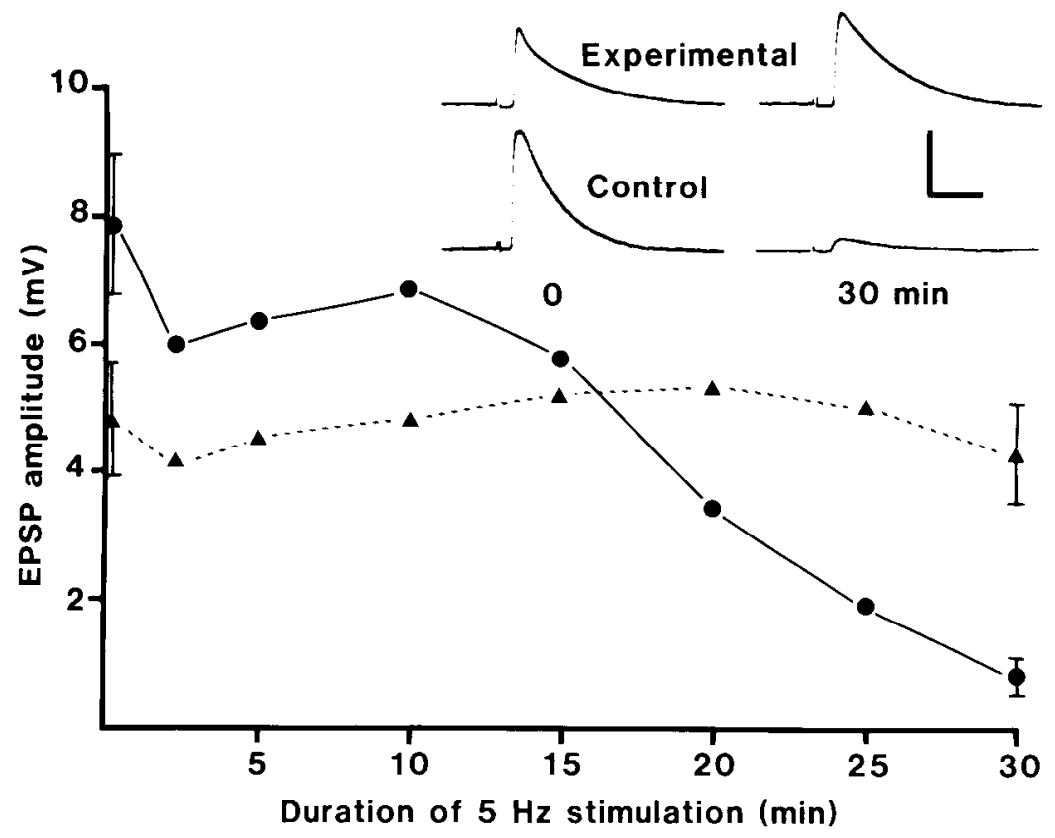

Figure 4. Effect of imposed tonic activity upon the fast axon synaptic properties in intermediate-sized animals. The fast axon in the experimental claw was stimulated for $2 \mathrm{hr} /$ day at $5 \mathrm{~Hz}$ for 14 days. EPSP values represent mean values from 10 fibers in five experimental claws $(\mathbf{A})$ and 10 fibers from the five contralateral control claws (-). Bars indicate the standard error of the mean. Inset, Representative EPSPs from an experimental claw and the contralateral control. Calibration: $20 \mathrm{msec}, 4 \mathrm{mV}$. 
Figure 5. Measurement of transmitter release through focal recording of synaptic current in a control claw. The amount of transmitter released at active sites was measured in experimental and control claws to determine whether the greater synaptic endurance in the experimental claw is due to greater transmitter release during prolonged activation. Transmitter release was measured by locating active sites with extracellular current measuring electrodes and recording the evoked synaptic current along with the quantal currents. The above records are from an experimental claw after 40 min of stimulation at $5 \mathrm{~Hz}$. $A$, Records of evoked synaptic currents showing late releases of transmitter (arrows). These asynchronous releases of transmitter were used to determine the current amplitude produced by a single quantum of transmitter. $B$, A typical evoked response from this active site showing no asynchronous release of transmitter. The arrow indicates nerve terminal current. $C$, Signal average of 256 responses from this active site after $40 \mathrm{~min}$ of stimulation at $5 \mathrm{~Hz}$. Calibration: $10 \mathrm{msec}$, $0.5 \mathrm{nA}$.

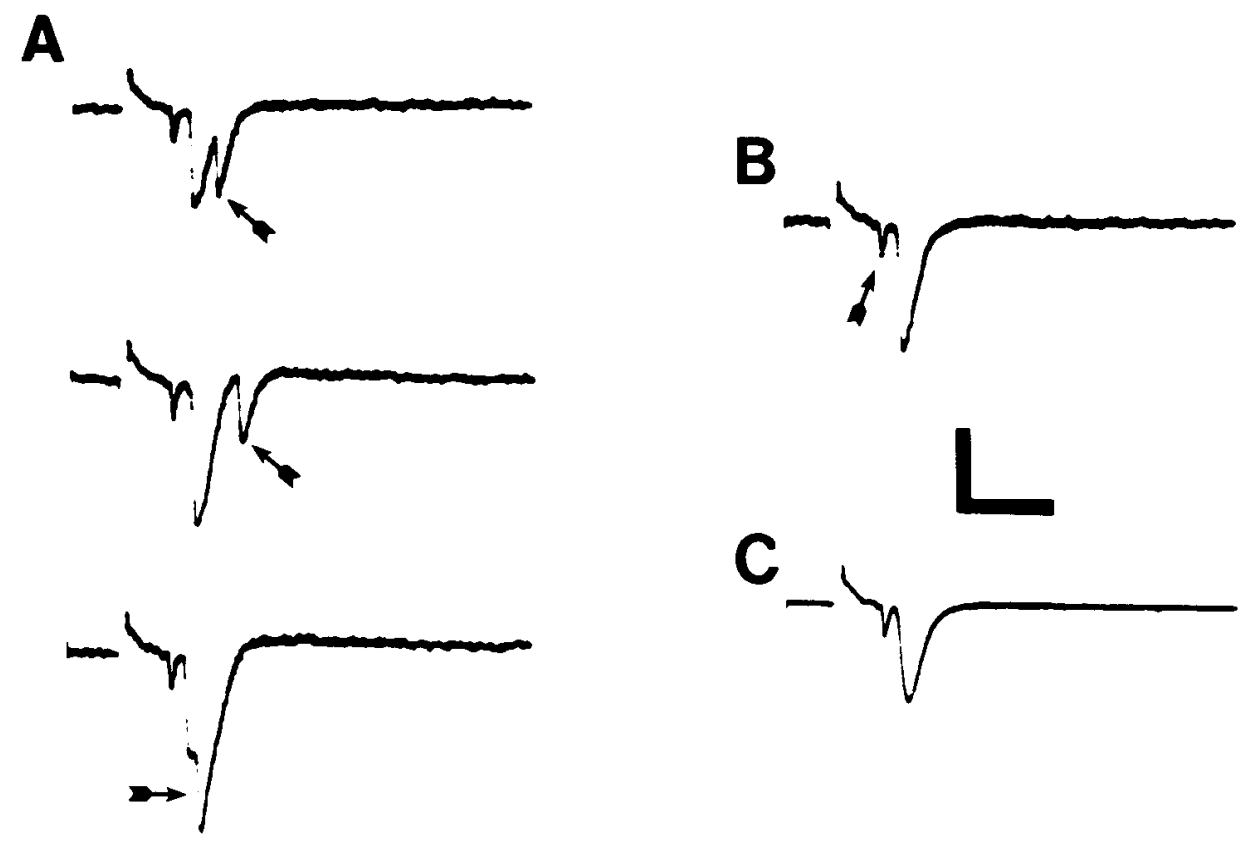

Figure 6. The effect of imposed tonic activity upon the fast axon synaptic properties in small adults. The fast axon in small adult cravfish was provided with the same regimen of chronic stimulation as in the intermediatesized crayfish. EPSP amplitudes represent mean values from 10 fibers in five experimental claws ( $\mathbf{A})$ and 10 fibers from the five contralateral control claws (-). Bars indicate the standard error of the mean.

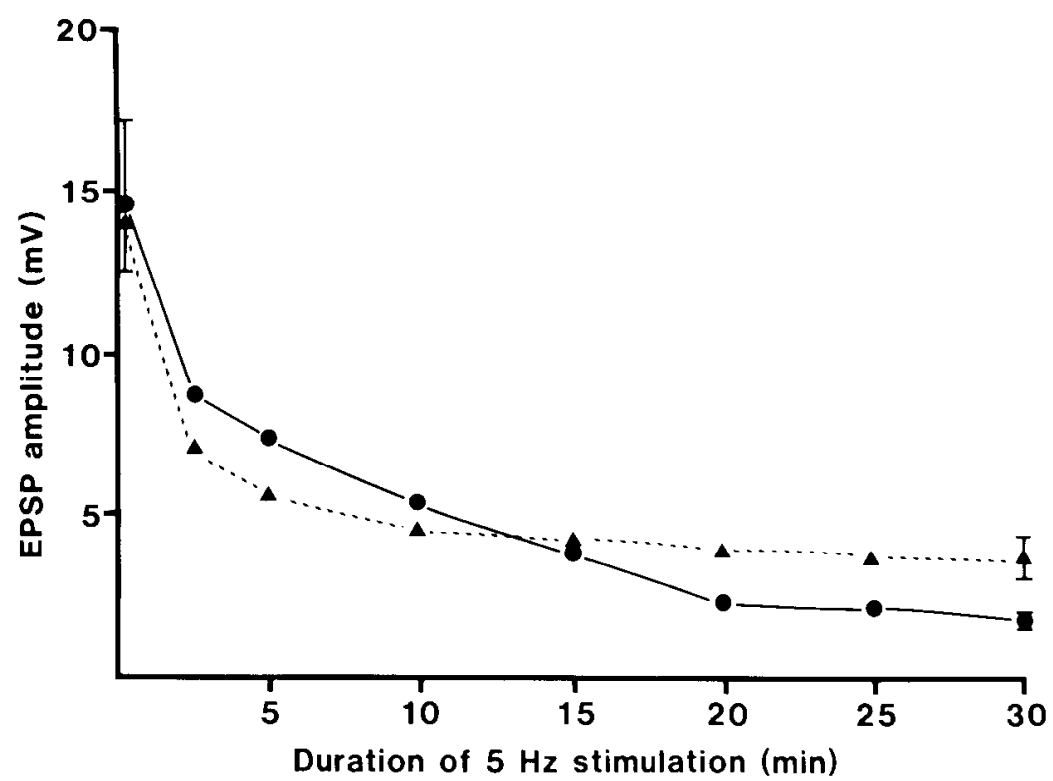

chronic stimulation. Before each daily 2 -hr stimulation, the initial peak-to-peak myogram amplitude was measured during low frequency $(0.01 \mathrm{~Hz})$ stimulation. The myogram depression was then measured during the first $30 \mathrm{~min}$ of the $2 \mathrm{hr}$ of $5 \mathrm{~Hz}$ stimulation. The synaptic endurance was determined by the ratio of final myogram amplitude to initial myogram amplitude (Fig. 7).

The myogram, representing synchronous electrical activity of all of the fibers in the closer muscle, may not provide an accurate measure of changes in the initial EPSP during the chronic stimulation regimen. Since, during low-frequency activation of the fast axon, the central closer muscle fibers often produce spikes, long-term changes in the initial synaptic current could be masked by the current generated by the nonsynaptic membrane. However, during maintained $5-\mathrm{Hz}$ stimulation, the spikes disappear and the myogram represents only the synaptic currents. Therefore, although the myogram records allow us to follow changes occurring in a single animal, they are probably not as sensitive to changes as the acute measurements of EPSP amplitudes. Thus, acute experiments in which EPSP amplitudes of identical muscle fibers could be accurately measured were used to verify conclusions initially based on myograms.

Myogram measurements indicate that the increase in synaptic endurance is largely established during the first 3 to 4 days of chronic stimulation. Following this observation, acute EPSP measurements were made. These showed that a significant increase in synaptic endurance occurs during the first 3 days of stimulation. The fast closer excitor in four intermediatesized crayfish was stimulated unilaterally for $2 \mathrm{hr} /$ day at $5 \mathrm{~Hz}$ for 3 days. One day after the final stimulation, fast axon EPSPs were measured in the identified muscle fibers. The initial EPSP was not significantly different $(p>0.05)$ in the experimental claws $(12.1 \pm 3.3 \mathrm{mV})$ compared to the contralateral controls $(11.0 \pm 3.3 \mathrm{mV})$. However, the EPSP amplitude after $30 \mathrm{~min}$ of stimulation at $5 \mathrm{~Hz}$ was significantly larger $(p<0.05)$ in the 
TABLE I

Changes in fast axon synaptic properties produced by 2 weeks of imposed tonic activity

The effect of imposed tonic activity was determined by calculating the synaptic endurance (EPSP amplitude after $30 \mathrm{~min}$ of stimulation at $5 \mathrm{~Hz}$ /initial EPSP amplitude) and comparing the endurance of the experimental and control fast excitor synapses. Synaptic endurance was calculated for individual fibers and the mean values for all of the experimental and control fibers from each size class were determined. The change in synaptic endurance values was determined for each animal by dividing the mean synaptic endurance of its experimental claw by the mean synaptic endurance of the contralateral control claw. The change in synaptic endurance calculated for individual animals was then used to calculate the mean values for the various size classes. All EPSP values were adjusted using Martin's correction for nonlinear summation (Martin, 1955) prior to calculation of the synaptic endurance. In both the intermediate-sized crayfish and the combined adult data, the synaptic endurance of the experimental fibers was significantly greater than the control $(p<0.05)$. The change in synaptic endurance in the intermediate-sized crayfish was significantly greater than in the combined adult animals $(p<0.05)$.

\begin{tabular}{|c|c|c|c|}
\hline \multirow{2}{*}{$\begin{array}{l}\text { Crayfish Size } \\
\text { Class }\end{array}$} & \multicolumn{2}{|c|}{$\begin{array}{l}\text { Synaptic Endurance } \\
\quad(\text { mean } \pm S E)\end{array}$} & \multirow{2}{*}{$\begin{array}{l}\text { Change in Endurance } \\
\text { (mean } \pm \mathrm{SE} \text { ) of } \\
\text { Experimental/Control }\end{array}$} \\
\hline & Experimental & Control & \\
\hline Intermediate & $\begin{array}{c}1.36 \pm 0.46 \\
(n=10)\end{array}$ & $\begin{array}{c}0.16 \pm 0.05 \\
(n=10)\end{array}$ & $\begin{array}{c}11.3 \pm 4.8 \\
(n=5)\end{array}$ \\
\hline Small adult & $\begin{array}{c}0.24 \pm 0.04 \\
(n=10)\end{array}$ & $\begin{array}{c}0.16 \pm 0.03 \\
(n=10)\end{array}$ & $\begin{array}{l}1.9 \pm 0.5 \\
(n=5)\end{array}$ \\
\hline I arge adult & $\begin{array}{c}0.09 \pm 0.02 \\
(n=9)\end{array}$ & $\begin{array}{l}0.04 \pm 0.01 \\
\quad(n=8)\end{array}$ & $\begin{array}{l}2.9 \pm 0.9 \\
(n=4)\end{array}$ \\
\hline
\end{tabular}

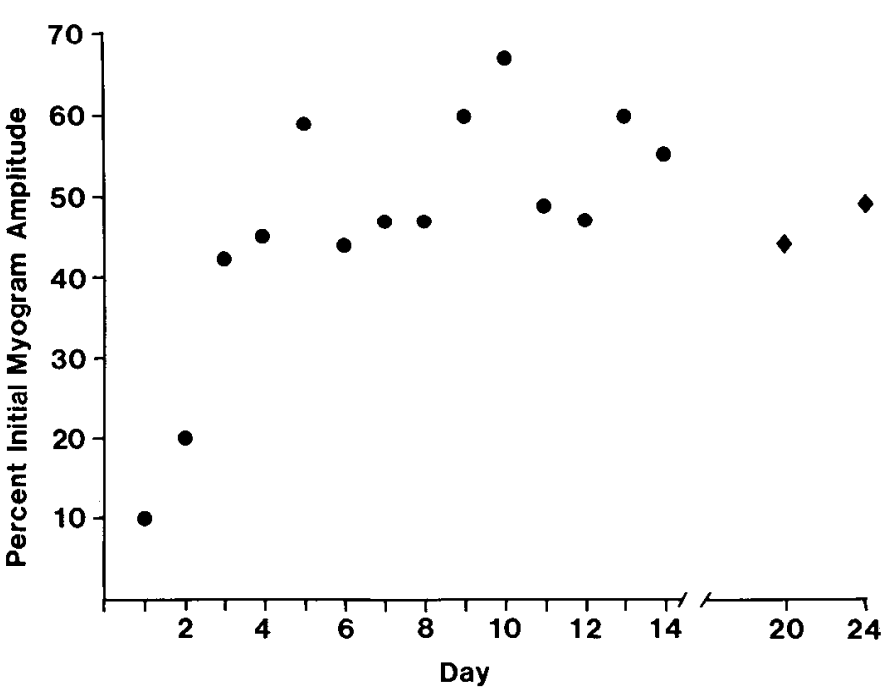

Figure 7. Change in synaptic properties during chronic stimulation. During the chronic stimulation regimen the peak-to-peak myogram amplitude was measured during the first $30 \mathrm{~min}$ of the daily $2 \mathrm{hr}$ stimulation. The myogram amplitude after $30 \mathrm{~min}$ of stimulation was divided by the initial myogram amplitude (eight stimulations at 0.01 $\mathrm{Hz}$ ) to determine the synaptic endurance for each stimulation day $(\bullet)$. After the end of the 14 days of chronic stimulation, stimulation was discontinued except for days 20 and 24 when the fast axon was stimulated for $30 \mathrm{~min}$ at $5 \mathrm{~Hz}$ to test the synaptic properties $(\diamond)$. No appreciable decline in synaptic endurance occurred during this period of rest. experimental claws $(5.0 \pm 1.0 \mathrm{mV})$ compared to the contralateral control claws $(1.3 \pm 0.2 \mathrm{mV})$. Thus, it appears that, although the increase in the final EPSP amplitude is largely established during the first 3 days, the change in the initial EPSP amplitude does not occur until after 3 days of stimulation. The failure of the myogram records to show a significant decrease in the initial EPSP amplitude between stimulation days 3 and 14 is probably due to the contribution of muscle spikes to the myogram as stated previously.

Change in synaptic properties is long-lasting. The earlier acute measurements of synaptic performance indicated that the longlerm adaptation was evident 1 day following the final chronic stimulation period. To determine whether long-term adaptation lasted longer than 1 day, the myogram amplitudes were measured during 30 -min stimulation periods, 6 and 10 days (days 20 and 24) after the final day of the 2-week chronic stimulation regimen (Fig. 7). According to these measurements, the increase in synaptic endurance persists for 10 days after the final day of stimulation.

The persistence of the long-term adaptation was further supported by acute EPSP measurements. Measurements of EPSP amplitudes in claws taken from crayfish stimulated for only 3 days indicate that long-term adaptation still exists after 1 week of rest. The fast axon in four intermediate-sized crayfish was stimulated unilaterally for $2 \mathrm{hr} /$ day at $5 \mathrm{~Hz}$ for 3 days. After 1 week of rest, the fast axon's synaptic properties were compared in experimental and control claws. The EPSP amplitude after $30 \mathrm{~min}$ of stimulation at $5 \mathrm{~Hz}$ was significantly larger $(p<0.05)$ in the experimental claws $(5.67 \pm 1.17 \mathrm{mV} ; n$ $=8$ ) compared to the contralateral control claws ( $2.97 \pm 0.87$ $\mathrm{mV} ; n=8$ ). Thus, even relatively short regimens of chronic stimulation produce long-lasting changes in synaptic properties of the fast axon.

\section{Discussion}

Possible mechanisms underlying long-term adaptation. In young crayfish, the phasic synapses adapt to imposed tonic activity by releasing less transmitter during brief low frequency activation and more transmitter during repetitive stimulation. Reduced transmitter release during low frequency activation of the experimental synapses is indicated by the smaller EPSP amplitude, which cannot be accounted for by changes in the electrical properties of the muscle fibers. The increase in transmitter release during prolonged repetitive activation was established by direct measurements of the quantal release of transmitter at active sites.

Due to the relatively low threshold for excitation of the fast axon (it is the largest axon in the leg nerve), it is assumed that relatively few sensory fibers, neurosecretory axons, or other motoneurons are activated during chronic stimulation. However, even if other axons are stimulated, coactivation of other motoneurons would not be expected to produce the change we observe in the fast axon's synaptic properties. According to present information, stimulation of neurosecretory axons would produce potentiation but not the semi-permanent changes observed during long-term adaptation. Both serotonin and octopamine produce enhanced transmitter release in lobster and crayfish motor axons (Breen and Atwood, 1983; Glusman and Kravitz, 1982), but the effects wear off with time courses of minutes to hours. The effects reported here are longer lasting, persisting for many days.

It is known that synaptic connections (probably monosynaptic) exist between claw sensory neurons and motoneurons, and also that cross-connections occur centrally between various claw motoneurons (Wiens, 1976, 1982; Wiens and Gerstein, 1976; Wiens and Atwood, 1978). Thus, activity in sensory or motoneurons other than the fast axon could cause depolarizing synaptic potentials in the central processes of the fast moto- 
neuron, even when no spikes are generated by this neuron. Stimulation of sensory and other motor axons might contribute to the observed changes if the depolarization of the fast excitatory motoneuron is involved centrally in triggering the changes we observe. Similarly, chronic stimulation of the fast axon could exert its effect on fast axon synapses through the activity it produces in the terminals, or through depolarization produced by antidromic invasion of the spike into the cell body or central neuropilar processes of the neuron.

The reduction in the low frequency EPSP amplitude can only be produced by changes in pre-existing synapses. Based upon previous work at the crustacean neuromuscular junction, possible explanations could include a reduction in the size and/ or number of dense bars, which are thought to be sites of transmitter release (Atwood, 1982). Studies of synaptic ultrastructure indicate that the amount of transmitter released during low frequency stimulation correlates with the size and/ or number of dense bars in the crab (Atwood and Marin, 1983) and the lobster (Govind and Chiang, 1979; Govind and Meiss, 1979; Govind et al., 1982). However, a comparison of the total area of dense bars and the amount of transmitter released per unit length of crab terminal suggests that other factors such as calcium channel density may play a role (Atwood and Marin, 1983).

According to the "depletion hypothesis," synaptic depression at neuromuscular junctions is produced by a decrease in the "readily releasable" transmitter store. It is presently unclear whether the depression which occurs at many synapses during the initial EPSPs of a train is attributable to depletion (Betz, 1970; Zucker and Bruner, 1977; Bryan and Atwood, 1981). However, it appears that the gradual rundown during long trains reflects depletion from a releasable store partially counteracted by replenishment through mobilization of transmitter (Elmquist and Quastel, 1965; Lass et al., 1973). The increase in synaptic endurance produced by chronic stimulation may be due to an increased rate of transmitter mobilization.

It should be noted that the greater transmitter release during prolonged stimulation of the experimental fast axons cannot be the result of more available transmitter due to the smaller initial relcase of transmitter. This is evidenced by the different time courses for the establishment of the two effects. The greater maintained transmitter release occurs before the decrease in the initial amplitude is observed.

The cellular events underlying transmitter mobilization and reuptake are probably energy dependent, and during long trains transmitter release could be limited by the rate of energy metabolism. Tonic vertebrate motoneurons appear to have a greater capability for oxidative respiration than their phasic counterparts. The activity of NADH-diaphorase, an enzyme indicative of oxidative capacity (Nachlas et al., 1958), has been shown to be greater in motoneurons innervating slow-twitch oxidative fibers than in those innervating fast-twitch glycolytic fibers (Sickles and Oblak, 1984). Greater oxidative capacity in tonic axons is further supported by ultrastructural studies of phasic and tonic nerve terminals, which show that tonic axon terminals possess more mitochondria than do phasic axon terminals (Atwood and Johnston, 1968; Atwood and Jahromi, 1978).

Cells can adapt to changing energy demands through an alteration in the activity of their metabolic enzymes. Continuous electrical stimulation of fast-twitch skeletal muscle produces metabolic changes which include a decrease in the activity of the enzymes of anaerobic metabolism and an increase in the activity of the enzymes of aerobic metabolism (for review see Salmons and Henriksson, 1981). Ultrastructurally, there is a corresponding incease in muscle mitochondrial content (Salmons et al., 1978). It would seem reasonable that motoneuron energy metabolism would show plasticity similar to that of muscle, in order that motoneuron and muscle fibers would remain matched during alterations in usage.

Decreased plasticity during aging. The effect of a standard regimen of imposed tonic activity upon synaptic properties is less dramatic in older animals than in young animals. This decrease in modifiability during maturation of the crayfish neuromuscular junction is consistent with that reported for many central synapses, including those in the visual system of cats (Hubel and Wiesel, 1970; Blakemore and Van Sluyters, 1975) and locusts (Bloom and Atwood, 1980) and in the audiroty system of crickets (Matsumoto and Murphey, 1978).

The greater plasticity of young crayfish is possibly related to the fact that the neuron is still in the process of growing. During growth of crustaceans, there is an increase in the transmitter released from active sites at the neuromuscular junction (DeRosa and Govind, 1978; Lnenicka and Mellon, 1983). This increase is probably due to an increase in the size and/or density of the synapses and possibly an increase in the number of dense bars per synapse (Atwood and Kwan, 1976; Govind, 1982). Thus, it seems reasonable that the transcriptional and/or translational machinery involved in the production of synaptic proteins might be more active in smaller animals and thus more susceptible to regulatory control. Assuming that these plastic changes require quantitative or qualitative changes in synaptic proteins, they might be more readily produced in small animals. Also, in smaller animals the soma has fewer synapses to serve and, hence, a smaller volume ratio of terminal arborizations to soma. Thus, equal changes in synaptic proteins would be more effective in small animals.

Adaptive differentiation of central and neuromuscular synapses. We find that the properties of an identified group of neuromuscular synapses gradually become better suited for a phasic pattern of activation during postnatal development. The imposition of tonic activity during development appears to alter this trend, causing the synaptic properties to become nore similar to those of tonic axons. These results suggest that the level of motoneuron activity could play a role in the differentiation of phasic and tonic synaptic types during normal development. However, this cannot be conclusively tested unless the fast axon activity is continually altered during development from intermediate-sized to adult crayfish.

In the rat, chronic stimulation of predominantly phasic motoneurons did not cause the transmitter release properties of neuromuscular synapses to resemble those of tonic motoneurons (Gertler and Robbins, 1978) as we report in the crayfish. However, our study is probably more sensitive to activitydependent changes in synaptic properties due to the ability to alter the activity and measure the synaptic properties of an identified group of synapses of a single motoneuron. In addition, the fast closer excitor is normally an extremely inactive motoneuron showing more dramatic depression than the typical vertebrate phasic motoneuron. The imposition of tonic activity in our study represents a dramatic change in the activity of the fast axon from the normal level of 10.5 impulses/day to 36,000 impulses/day. Therefore, it may be more dramatically altered by imposed tonic activity than are vertebrate motoneurons. Finally, in the previous study on rats, age was not taken into consideration and may be an important factor, as it has proven to be for modifiability of crayfish neuromuscular synapses.

Other studies provide evidence for the generality of these findings. In juvenile lobsters, the fast axon synapses of the closer muscle of both claws are fatigue resistant (Costello et al., 1981). After differentiation of the claws into a specialized "cutter" and "crusher," the cutter fast axon synapses become fatigueable, whereas those of the crusher remain more resistant to fatigue (Govind and Lang, 1974). During claw differentiation, there is a permanent decrease in the activity of the cutter claw (Walter J. Costello, personal communication). 'Ihus, the dif- 
ferent acitivity levels in the two claws might be responsible for the differences in synaptic fatigueability.

In the locust, decreased activity of central synapses during development results in greater synaptic depression. A decrease in the activity of the locust movement detector system during development through deprivation of visual input results in greater habituation to a standard stimulus. This abnormal rate of habituation is apparently due to an increased rate of fatigue at central synapses (Bloom and Atwood, 1980). This increased synaptic depression after abnormally low levels of activity is consistent with our finding that the fatigueability of synapses will adapt to their level of ongoing activity.

\section{References}

Atwood, H. L. (1973) Crustacean motor unit. In Control of Posture and Locomotion, R. B. Stein, ed., pp. 87-104, Plenum Press, New York.

Atwood, H. L. (1982) Synapses and neurotransmitters. In The Biology of Crustacea. Vol. 3: Neurobiology: Structure and Function H. L. Atwood, and D. C. Sandeman, eds., pp. 105-150, Academic Press, Inc., New York.

Atwood, H. L., and S. S. Jahromi (1978) Fast-axon synapses in crab leg muscle. J. Neurobiol. 9: 1-15.

Atwood, H. L., and H. S. Johnston (1968) Neuromuscular synapses of a crab motor axon. J. Exp. Zool. 167: 457-470.

Atwood, H. L., and I. Kwan (1976) Synaptic development in the crayfish opener muscle. J. Neurobiol. 7: 289-312.

Atwood, H. L., and L. Marin (1983) Ultrastructure of synapses with different transmitter-releasing characteristics on motor axon terminals of a crab, Hyas areneas. Cell Tissue Res. 231: 103-115.

Betz, W. J. (1970) Depression of transmitter release at the neuromuscular junction of the frog. J. Physiol. (Lond.) 206: 629644 .

Blakemore, C., and R. C. Van Sluyters (1975) Innate and environmental factors in the development of the kitten's visual cortex. J. Physiol. (Lond.) 248: 663-716.

Bloom, J. W., and H. L. Atwood (1980) Effects of altered sensory experience on the responsiveness of the locust descending contralateral movement detector neuron. J. Comp. Physiol. 135: 191-199.

Breen, C. A., and H. L. Atwood (1983) Octopamine-A neurohormone with presynaptic activity-dependent effects at crayfish neuromuscular junctions. Nature 303: 716-718.

Bryan, J. S., and H. L. Atwood (1981) Two types of synaptic depression at synapses of a single crustacean motor axon. Marine Behav. Physiol. 8: $99-121$

Costello,W. J., R. Hill, and F. Lang (1981) Innervation patterns of fast and slow motor neurones during development of a lobster neuromuscular system. J. Exp. Biol. 91: 271-284.

Crawford, A. C., and R. M. McBurney (1976) On the elementary conductance event produced by L-glutamate at the neuromuscular junction of Maia squinado. J. Physiol. (Lond.) 258: 205-225.

DeRosa, R. A., and C. K. Govind (1978) Transmitter output increases in an identified lobster motoneuron with growth of its muscle fibers. Nature 273: 676-678.

Dudel, J., and S. W. Kuffler (1961a) The quantal nature of transmission and spontaneous miniature potentials at the crayfish neuromuscular junction. J. Physiol. (Lond.) 155: 514-529.

Dudel, J., and S. W. Kuffler (1961b) Mechanism of facilitation at the crayfish neuromuscular junction. J. Physiol (Lond.) 155: 530-542.

Elmquist, D., and D. M. J. Quastel (1965) A quantitative study of endplate potentials in isolated human muscle. J. Physiol. (Lond.) 178: 505-529.

Gertler, R. A., and N. Robbins (1978) Differences in neurotransmission in red and white muscles. Brain Res, 142: 160164.

Glusman, S., and E. A. Kravitz (1982) The action of serotonin on excitatory nerve terminals in lobster nerve-muscle preparations. J. Physiol. (Lond.) 325: 223-241.
Govind, C. K. (1982) Development of nerve, muscle, and synapse. In The Biology of Crustacea. Vol. 3: Neurobiology. Structure and Function. H. L. Atwood and D. C. Sandeman, eds., pp. 185-204, Academic Press, Inc., New York.

Govind, C. K., and R. G. Chiang (1979) Correlation between dense bodies and transmitter output at lobster neuromuscular synapses by serial section electron microscopy. Brain Res. 161: 377-388.

Govind, C. K., and F. Lang (1974) Neuromuscular analysis of closing in the dimorphic claws of the lobster Homarus americanus. J. Exp. Zool. 190: 281-288.

Govind, C. K., and D. E. Meiss (1979) Quantitative comparison of lowand high-output neuromuscular synapses from a motoneuron of the lobster (Homarus americanus). Cell Tissue Res. 198: 455-463.

Govind, C. K., D. E. Meiss, and J. Pearce (1982) Differentiation of identifiable lobster neuromuscular synapses during development. J. Neurocytol. 11: 235-247.

Hubel, D. H., and T. N. Wiesel (1970) The period of susceptibility to the physiological effects of unilateral eye closure in kittens. J. Physiol. (Lond.) 206: 419-436.

Johnson, E. W., and A. Wernig (1971) The binomial nature of transmitter release at the crayfish neuromuscular junction. J. Physiol. (Lond.) 218: 757-767.

Lass, Y., Y. Halen, E. M. Landau, and S. Gitter (1973) A new model for transmitter mobilization in the frog neuromuscular junction. Pflugers Arch. 343: 157-163.

Lnenicka, G. A., and DeF. Mellon (1983) Transmitter release during normal and altered growth of identified muscle fibers in the crayfish. J. Physiol. (Lond.) 345: 205-296.

Martin, A. R. (1955) A further study of the statistical composition of the end-plate potential. J. Physiol. (Lond.) 130: 114-122.

Matsumoto, S. G., and R. K. Murphey (1978) Sensory deprivation in the cricket nervous system: Evidence for a critical period. J. Physiol. (Lond.) 285: 159-170.

Nachlas, M. M., D. G. Walker, and A. M. Seligman (1958) A histochemical method for the demonstration of diphosphopyridine nucleotide diaphorase. J. Biophys. Biochem. Cytol. 4: 29-38.

Robbins, N., and G. D. Fischbach (1971) Effect of chronic disuse of rat soleus neuromuscular junctions on presynaptic function. J. Neuro. physiol. 34: 570-578.

Salmons, S., and J. Henriksson (1981) The adaptive response of skeletal muscle to increased use. Muscle Nerve 4: 94-105.

Salmons, S., D. R. Gale, and F. A. Sreter (1978) Ultrast ructural aspects of the transformation of muscle fiber type by long-term stimulation: Changes in $\mathrm{Z}$ dises and mitochondria. J. Anat, 127:17-31.

Sickles, D. W., and T. G. Oblak (1984) Metabolic variation among $\alpha$ motoneurons innervating different muscle fiber types. I. Oxidative enzyme activity. J. Neurophysiol. 51: 529-537.

Van Harreveld, A. (1936) A physiological solution for freshwater crustaceans. Proc. Soc. Exp. Biol. Med. 34: 428-432.

Wiens, T. J. (1976) Electrical and structural properties of crayfish claw motoneurons in an isolated claw-ganglion preparation. J. Comp. Physiol. 112: 213-233.

Wien:, 'l'. J. (1982) Small systems of neurons: Control of rhythmic and reflex activity. In The Biology of Crustacea. Vol. 4: Neural Integration and Behavior, D. C. Sanderman and H. L. Atwood, eds., pp. 193-240, Academic Press, Inc., New York.

Wiens, T. J., and H. L. Atwood (1978) Motoneuron interactions in crayfish claw control: Fvidence from int racellular recording. J. Comp. Physiol. 124: 237-247.

Wiens, T. J., and G. L. Gerstein (1976) Reflex pathways of the crayfish claw. J. Comp. Physiol. 107: 309--326.

Wiersma, C. A. G. (1961) The neuromuscular system. In The Physiology of Crustacea. Vol. 2: Sense Organs, Integration, and Behavior. T. H. Waterman, ed., pp. 191-240, Academic Press, Inc., New York.

Zucker, R. S., and J. Bruner (1977) Long-lasting depression and the depletion hypothesis at crayfish neuromuscular junctions. J. Comp. Physiol 121: 223-240. 